fournal of Medical Genetics (1971). 8, 240.

\title{
The Use of Quinacrine Fluorescence in the Identification of B and E Group Chromosomes Involved in Structural Abnormalities
}

\author{
M. BOBROW and P. L. PEARSON \\ From MRC Population Genetics Unit, Oxford
}

Since completion of the report on our patient (A.P.) with the complex karyotype $46, \mathrm{XY}, 4 \mathrm{r}, \mathrm{E}-$, $t(B q E q)$ described in the previous paper (pp. 235239), a powerful new tool has become available to human cytogeneticists. When stained with some quinacrine dyes, specific human chromosome regions (of which the largest is on the $\mathrm{Y}$ chromosome) exhibit intense fluorescence (Zech, 1969; Pearson, Bobrow, and Vosa, 1970). In addition, subtle banding patterns appear (Caspersson et al, 1970c) which are sufficiently characteristic to allow the identification of all chromosomes in the human complement except for Nos. 19 and 20. We describe here the identification of chromosomes in the $B$ and $E$ groups, based on studies of various cases, and apply the method to further defining the chromosomal abnormality in patient A.P.

\section{Methods}

Chromosome preparations from peripheral blood cultures were stained for about five minutes in a $0.5 \%$ aqueous solution of quinacrine dihydrochloride (Atebrin, G. Gurr). After brief rinsing in tap water, the slides were dried and mounted in distilled water. The optical system has been described previously (Pearson et al, 1970). Photographs were taken on Kodak Pan-X $35 \mathrm{~mm}$ film. A double beam scanning microdensitometer* was used to obtain optical density profiles down the length of each chromosome. Scanning is directly from the photographic negative, eliminating the extra photographic process necessitated by reflection scanning of bromide prints.

In addition to the case under discussion, four other individuals studied have provided information relevant to the $B$ and $E$ group chromosomes. (1) Two cases of cridu-chat syndrome, one confirmed as $5 p-$ by autoradiography. (2) One subject with a familial abnormal band of intense fluorescence on one No. 4 chromosome. (3) A case with an $\mathrm{E}$ ring; on autoradiography, 12/15 informa-

Received 12 February 1971.

* Joyce, Loebl \& Co. Ltd. tive metaphases contained two lightly labelled and one heavily labelled chromosome $17-18$, identifying the ring by exclusion as a No. 18 .

\section{Results}

Fluorescent studies on all patients yielded consistent results. Chromosome No. 4 can be readily distinguished from No. 5, and No. 17 from No. 18, either visually at the microscope, or by densitometric scanning.

B group chromosomes (Fig. 1a-d). The fluorescence patterns of $\mathbf{B}$ group chromosomes have been described by Caspersson, Zech, and Johansson (1970b) and we are in broad agreement with their findings. Visually, No. 4 appears fairly evenly stained throughout its length. A narrow band is sometimes present on the juxtacentromeric end of the long arm. Neither end of the long arm appears particularly dull. This contrasts with No. 5, which has a broad bright band in the centre of the long arm, causing both the proximal area and the distal third to appear dull. A narrow bright band is present in the centre of the short arm of No. 5.

On densitometric tracings, the points which distinguish No. 4 from No. 5 are (i) the short arm of 4 sweeps smoothly up to the centromere, while No. 5 rises to a peak and then falls to the centromere. (ii) No. 4 may have a small peak next to the centromere on the long arm. (iii) The long arm of 4 is otherwise fairly uniform throughout, while No. 5 rises to a marked peak at about its midpoint, then falls to a low plateau which occupies the distal $\frac{1}{3}$ of its length.

Traces of the 45 normal B group chromosomes from 15 cells of patient A.P. were transferred to individual pieces of tracing paper and marked only with randomly allocated code numbers. Two experienced observers (M.B. and P.L.P.) and one 


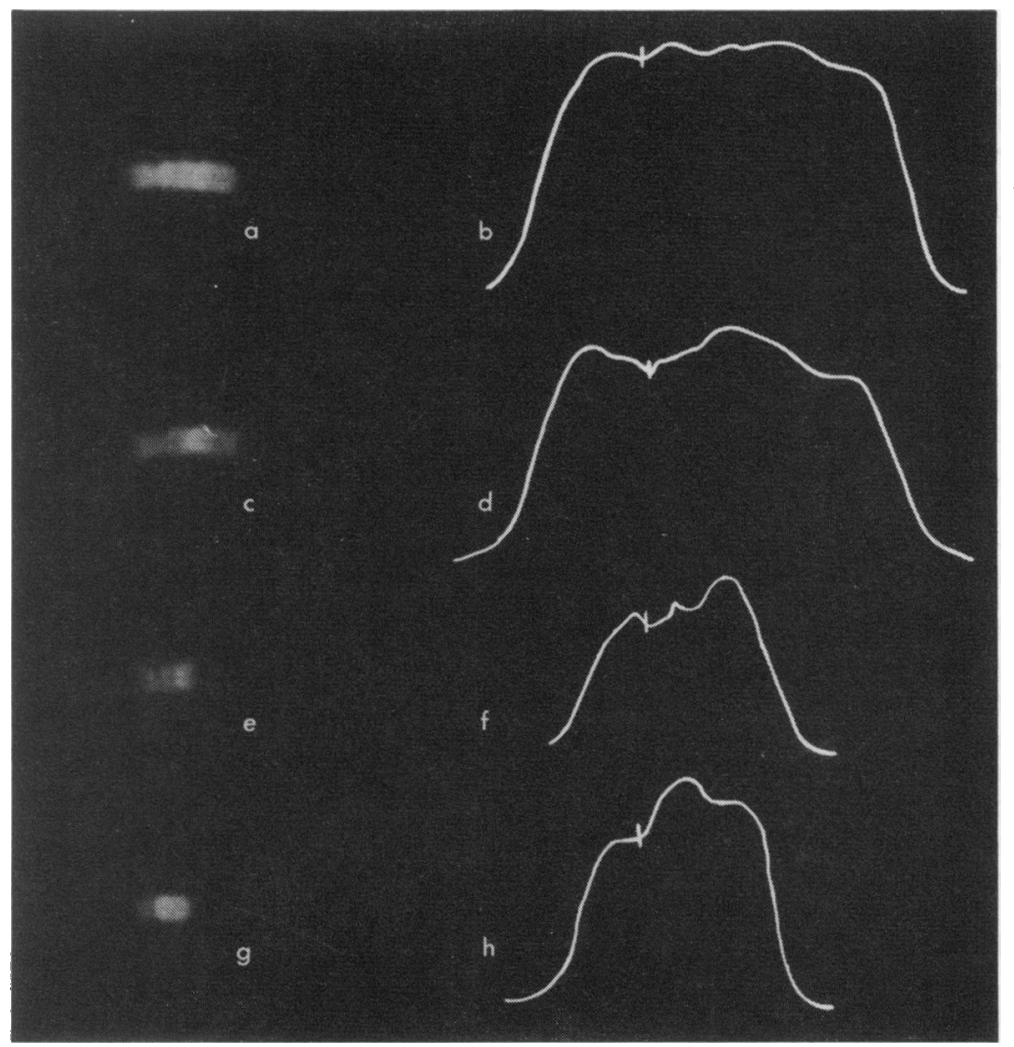

FIG. 1. Fluorescent photomicrographs and densitometric traces of typical $B$ and $E$ group chromosomes: $a$ and $b=$ No. $4 ; c$ and $d=$ No. 5 ; and $\mathrm{f}=$ No. $17 ; \mathrm{g}$ and $\mathrm{h}=$ No. 18 . (The short vertical line marks the apparent position of the centromere.)

cytologist with very limited experience of this technique (G.C.) then sorted the chromosome tracings into chromosomes No. 4 and 5 . Although some tracings were difficult to interpret, a decision was forced on each one. All three observers agreed on the classification of 39 out of the 45 chromosomes. The chromosome identifications were then regrouped in threes according to the cell of origin. Since the chromosomes had been scored individually, a cell could theoretically have been allocated the chromosome constitution 444, 445,455 , or 555 . The actual numbers of cells in each group is given for each observer in Table I.

It is clear that, despite a considerable variation between individual traces, a qualitative judgement of the chromosome represented can be made with a high degree of accuracy. In this case we confirm the autoradiographic evidence that the B chromosome involved in the ring is No. 4. On direct visual analysis of 17 further cells down the microscope, 14 were readily identified as containing one No. 4 and two No. 5 chromosomes.
In both cases of cri-du-chat syndrome, the abnormal chromosome had the fluorescence pattern of a No. 5 .

E group chromosomes (Fig. 1e-h). Since chromosome 16 can usually be identified morphologically, only Nos. 17 and 18 will be considered here. Both of these typically have two bands on the long arm, but in No. 17 the distal one is considerably brighter than the proximal, which can often not be seen. In No. 18, the intensities of the bands are more equal, but the brightest point on the long arm is in its proximal half. Chromosome 18 fluoresces with a greater overall brightness than No. 17 and the pairs can often be distinguished on this basis. In particular, the proximal third of the long arm of 18 is bright, while the corresponding area on 17 is very dull. These differences are reflected in the densitometric tracings which can be adequately separated on the basis of whether the highest peak on the long arm is in its proximal or distal half. Autoradiographic identification of the E-group in patient 
TABLE

NUMBER OF CELLS HAVING A PARTICULAR CHROMOSOME CONSTITUTION, ON THE BASIS OF 'BLIND' SCORING OF INDIVIDUAL CHROMOSOMAL DENSITOMETRIC TRACES

\begin{tabular}{|c|c|c|c|c|}
\hline \multirow[t]{2}{*}{ Observer } & \multicolumn{4}{|c|}{ Chromosome Constitution } \\
\hline & $4,4,4$ & $4,4,5$ & $4,5,5$ & $5,5,5$ \\
\hline \multirow[t]{2}{*}{$\begin{array}{c}\text { B-group (15 cells) } \\
\quad 1 \\
2 \\
3\end{array}$} & $\begin{array}{l}0 \\
0 \\
0\end{array}$ & $\begin{array}{l}1 \\
1 \\
1\end{array}$ & $\begin{array}{l}13 \\
12 \\
12\end{array}$ & $\begin{array}{l}1 \\
1^{*}\end{array}$ \\
\hline & $17,17,17$ & $17,17,18$ & $17,18,18$ & $18,18,18$ \\
\hline $\begin{array}{l}\text { E-group }(12 \text { cells }) \\
\quad 1 \\
2 \\
3\end{array}$ & $\begin{array}{l}0 \\
0 \\
0\end{array}$ & $\begin{array}{r}12 \\
8 \\
11\end{array}$ & $\begin{array}{l}0 \\
2 \\
1\end{array}$ & $\begin{array}{l}0 \\
0^{*} \\
0\end{array}$ \\
\hline
\end{tabular}

* Observer 2 scored fewer cells than observers 1 and 3.

A.P. was unsatisfactory, but a patient with an E-ring was studied in whom autoradiography had shown the ring to be derived from No. 18. Thirteen out of 16 cells examined under the fluorescent microscope were found to contain two No. 17 and one No. 18 chromosome.

Twenty-one cells of patient A.P. were analysed at the microscope; in 18 of these, two No. 17 and one No. 18 chromosome were identified. Individual densitometric tracings of the E-group members from 12 cells were scored in a similar experiment to that described for the B-group. Agreement between all observers was found for $33 / 36$ chromosomes. The results, regrouped into cells, are shown in Table I. The missing chromosome is clearly identified as a No. 18.

The translocation (Fig. 2). In patient A.P., the missing No. 18 chromosome is replaced by a metacentric chromosome slightly larger than the D-group. The fluorescent banding pattern of one arm of this translocation chromosome corresponds very well with the long arms of No. 18. It is more difficult to decide on whether the other arm represents the long or the short arm of a No. 4 , as there are no distinctive features in this region. The edge of the long arm does, however, usually rise more steeply than that of the short arm, and in the majority of cells the pattern of the translocation chromosome could be more satisfactorily fitted to the curve of the long arm.

Approximately midway between the points at which the $4 \mathrm{q}$ and 18 tracings diverge from the tracing of the abnormal chromosome, a small notch can often be seen in the latter trace. It is suggested that this represents the joining point of the translocation segments. On this basis, the translocation chromosome contains about one third of the long arms of No. 4 and all of No. 18 except for the distal two thirds of the short arms. This $18 p$ material, and an unknown proportion of $4 \mathrm{p}$, have presumably been lost from the karyotype.

\section{Summary}

Fluorescence of human chromosomes stained with quinacrine dihydrochloride allows ready identification of members of the $B$ and $E$ groups. Applied to the study of a complex chromosomal rearrangement, this technique has confirmed that the abnormality involves a No. 4 chromosome and has demonstrated that it also involves a No. 18. The probable breakpoints of the translocation can be defined within quite narrow limits.

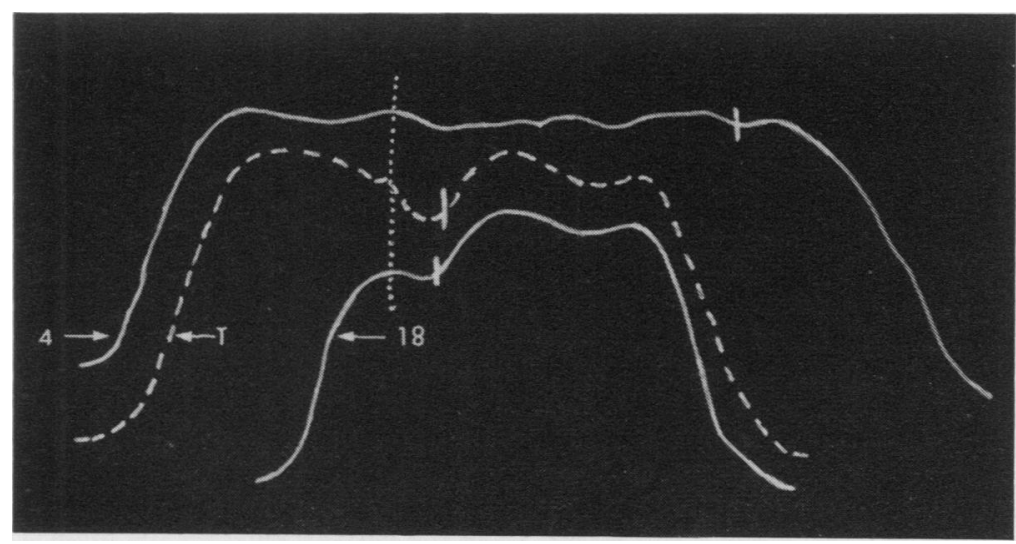

Fig. 2. Densitometric tracings of the translocation chromosome (T) and the normal chromosomes 4 and 18 from the same cell. (The dotted vertical line marks the postulated breakpoints of the translocation.) 
REFERENCES

Caspersson, T., Lindsten, J., and Zech, L. (1970a). Identification of the abnormal B-group chromosomes in the 'cri-du-chat' syndrome by QM-fluorescence. Experimental Cell Research, 61, 475-476.

Caspersson, T., Zech, L., and Johansson, C. (1970b). Quinacrine mustard fluorescence of human chromosomes 4,5 and X. Experimental Cell Research, 61, 474-475.

Caspersson, T., Zech, L., Johansson, C., and Modest, E. J. (1970c).
Identification of human chromosomes by DNA-binding fluorescent agents. Chromosoma, 30, 215-227.

Pearson, P. L., Bobrow, M., and Vosa, C. G. (1970). Technique for identifying $\mathbf{Y}$ chromosomes in human interphase nuclei. Nature, 226, 78-80.

Zech, L. (1969). Investigation of metaphase chromosomes with DNA-binding fluorochromes. Experimental Cell Research, 58, 463. 